trying to tell the truth. There was, however, a period of fifteen months between the recognition of mustard gas in the German shells and the use of it in British shells, although in the actual manufacture of the chemical product there was no delay.

London.

Arthur Marshall.

March 16.

\section{A Use for the Paramount Sorting System}

MCKAY ${ }^{1}$ has recently described certain advantages of the Paramount Sorting System in handling statistical data. Adopting McKay's method in a recent investigation, I observed other advantages which may interest workers who are less concerned with statistical methods. The system involves the use of specially perforated cards (Fig. 1), one card being used for each specimen. The range of variation encountered in any feature is divided into a convenient number of classes, and a special hole is

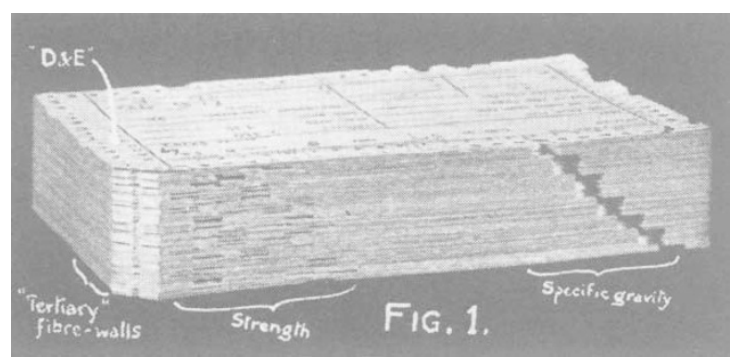

allotted to each class. To record the data for a particular specimen the appropriate hole is notched (hand tools can be obtained for this purpose). The edges visible in Fig. 1 show the recording of three interrelated features.

Once the data are recorded, the cards are easily sorted by pushing a rod through the hole representing any class and allowing the notched cards to fall out. The cards in Fig. 1 are arranged in order of specific gravity of specimens of timber under investigation, and the closeness of the relation between specific

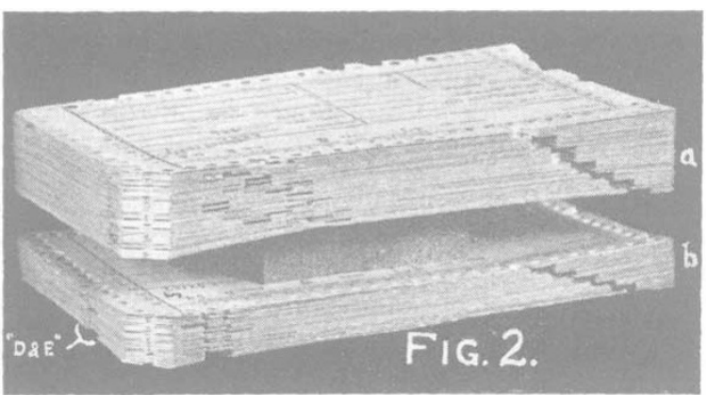

gravity and any other recorded feature may now be seen at once by glancing at the arrangement of the other notches. In the present instance the relation between strength and specific gravity was limited by the presence of 'tertiary walls' 2 in the wood fibres. Specimens with abundant tertiary walls (Fig. $2 b$ ) were segregated by pushing the rod through the holes $D$ and $E$. It may be seen that in the remainder (Fig. 2a) there is a distinct tendency for strength to increase with specific gravity. It is also a simple matter to recognise the cards of specimens which are unusual in respect of any feature and to pull out the card with all data recorded.

It is suggested that the method may be useful to investigators interested in the relations between three or more variables.

Needless to say, the time consumed in notching cards is much more than counterbalanced by the time saved in repeated sortings and by the time which would otherwise be spent in plotting graphs.

S. H. Clarke.

Forest Products Research Laboratory, Princes Risborough, Aylesbury, Bucks.

${ }^{1}$ Supp. to J. Roy. Stat. Soc., 1, $62(1934)$.
${ }^{2}$ NATURE, 128, 1078 (1931).

\section{Effect of Insulin on Plant Respiration}

THE concentration of blood sugar decreases after injection of insulin in man and other animals. Opinions, however, differ as to whether insulin brings about increased oxidation of carbohydrates ${ }^{1}$. Dhar and his collaboratcrs ${ }^{2}$ have found increased oxidation in vitro of sugars and other organic materials in a current of air in presence of insulin.

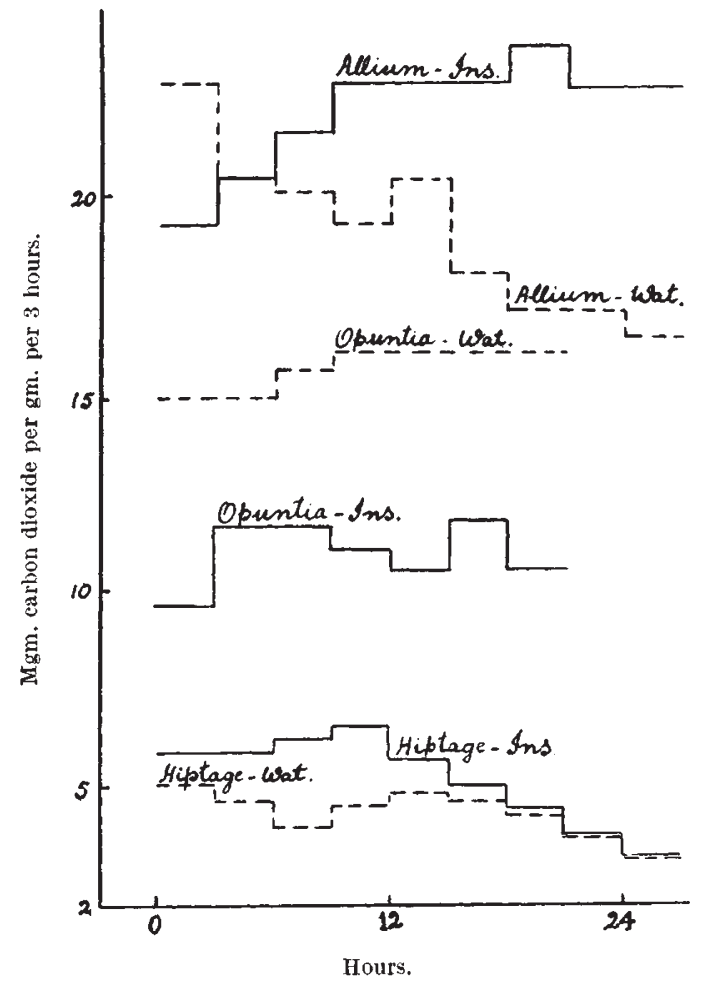

FIG. 1. Effect of injection of water and of insulin on plant respiration. Measurements for Hiptage were based on fresh weight and the others on their dry weights.

In order to note the effect of insulin on plant metabolism, a solution of insulin (40 units in 100 c.c.) was injected in plant materials by means of a vacuum pump. It was found that the leaves of Hiptage madablota and Allium tuberosum respired at a higher rate when injected with insulin than when injected with water. Phylloclades of Opuntia Dillenii into which insulin had been injected showed, however, a 